\title{
Impact of socioeconomic status on participation and outcomes in the Salford Lung Studies
}

\author{
Rupert Jones ${ }^{1}$, Andy Nicholls ${ }^{2}$, Dominy Browning (10 ${ }^{3}$, Nawar Diar Bakerly ${ }^{4,5}$, \\ Ashley Woodcock ${ }^{5,6}$, Jørgen Vestbo $\mathbb{1}^{5,6}$, David A. Leather ${ }^{7}$, Loretta Jacques ${ }^{8}$, \\ James Lay-Flurrie ${ }^{2}$, Henrik Svedsater ${ }^{9}$ and Susan Collier ${ }^{10}$
}

Affiliations: ${ }^{1}$ Community and Primary Health Care, Faculty of Health, Plymouth University, Plymouth, UK ${ }^{2}$ Clinical Statistics, GlaxoSmithKline plc., Uxbridge, UK. ${ }^{3}$ Respiratory Research and Development, GlaxoSmithKline plc., Brentford, UK. ${ }^{4}$ Salford Royal NHS Foundation Trust, Salford, UK. ${ }^{5}$ Division of Infection, Immunity and Respiratory Medicine, Manchester Academic Health Sciences Centre, The University of Manchester, Manchester, UK. ${ }^{6}$ Manchester University NHS Foundation Trust, Manchester, UK. ${ }^{7}$ Global Respiratory Franchise, GlaxoSmithKline plc., Brentford, UK. ${ }^{8}$ Clinical Sciences, GlaxoSmithKline plc., Uxbridge, UK. ${ }^{9}$ Value Evidence and Outcomes, GlaxoSmithKline plc., Brentford, UK. ${ }^{10}$ UK Medical, GlaxoSmithKline plc., Uxbridge, UK.

Correspondence: Rupert Jones, Community and Primary Health Care, Faculty of Health, Plymouth University, ITTC Building (N14), Plymouth PL6 8BX, UK. E-mail: rupert.jonesवplymouth.ac.uk

ABSTRACT COPD and asthma prevalence is associated with socioeconomic status (or "deprivation"), yet deprivation is rarely considered in typical large-scale efficacy randomised controlled trials that recruit highly selected patient populations. In this post hoc analysis of the Salford Lung Studies in COPD and asthma (two 12-month, open-label, effectiveness randomised controlled trials conducted in UK primary care), we evaluated the impact of patient deprivation on clinical outcomes with initiating fluticasone furoate/vilanterol versus continuing usual care.

Patients were categorised into deprivation quintiles based on postcode and a countrywide database of indices of deprivation, and trial outcomes by quintile were assessed.

$52 \%$ of patients in the COPD study were included in the most deprived quintile, contrasting with $20 \%$ in the asthma study. Greater deprivation was associated with higher rates of primary/secondary healthcare contacts and costs. However, the treatment effect of fluticasone furoate/vilanterol versus usual care for primary (COPD: moderate/severe exacerbations; asthma: Asthma Control Test responders at week 24) and secondary/other (healthcare consumption, adherence, treatment modifications, study withdrawals, exacerbations, serious adverse events) outcomes was similar across deprivation quintiles.

Our findings support the recruitment of participants from all socioeconomic strata to allow assessment of data generalisability to routine clinical practice.

@ERSpublications

Deprivation did not impact the main outcomes of the SLS, thus supporting recruitment of participants from all socioeconomic strata to randomised controlled trials for assessment of generalisability of study findings to routine clinical practice http://bit.ly/34qk9EH

Cite this article as: Jones $\mathrm{R}$, Nicholls A, Browning D, et al. Impact of socioeconomic status on participation and outcomes in the Salford Lung Studies. ERJ Open Res 2020; 6: 00193-2019 [https:// doi.org/10.1183/23120541.00193-2019].

This article has supplementary material available from openres.ersjournals.com

The Salford Lung Studies are registered at www.clinicaltrials.gov with identifier numbers NCT01551758 and NCT01706198. Anonymised individual participant data from this study plus the annotated case report form, protocol, reporting and analysis plan, dataset specifications, raw dataset, analysis-ready dataset and clinical study report are available for research proposals approved by an independent review committee. Proposals should be submitted to www. clinicalstudydatarequest.com. A data access agreement will be required.

Received: 06 Aug 2019 | Accepted after revision: 11 Dec 2019

Copyright $\odot$ ERS 2020. This article is open access and distributed under the terms of the Creative Commons Attribution Non-Commercial Licence 4.0. 


\section{Introduction}

Socioeconomic status is a key determinant of health outcomes [1]. The prevalence of COPD, which is generally regarded as a disease of deprivation, and asthma tends to be higher in more deprived areas $[2,3]$. Deprived patients may be under-represented in traditional randomised controlled trials (RCTs), which seldom, if ever, collect and report the socioeconomic status of their participants. Evidence suggests that only a limited proportion of patients with COPD or asthma are eligible for typical large efficacy RCTs [4-6]; thus, generalising trial findings to the broader population of patients seen in routine clinical practice (including deprived patients) is problematic.

The Salford Lung Studies (SLS) were pragmatic randomised trials in COPD and asthma set in routine clinical practice in the United Kingdom (UK) $[7,8]$. The SLS provided a unique opportunity to explore the frequency of deprivation in pragmatic RCTs and whether deprivation impacts the trial outcomes.

\section{Methods}

Patients and study design

The SLS in COPD and asthma were concurrent, prospective, 12-month, open-label RCTs that evaluated the clinical effectiveness and safety of initiating fluticasone furoate/vilanterol (FF/VI) versus continuing usual care (UC) for the treatment of COPD and asthma, respectively (SLS COPD ClinicalTrials.gov identifier: NCT01551758; and SLS asthma ClinicalTrials.gov identifier: NCT01706198). The studies were conducted in primary care practices across Salford and South Manchester, UK. The trial designs and primary results have been reported previously [7, 8]. Recruitment for SLS COPD preceded that of SLS asthma. Patient recruitment commenced in Salford, later extending to sites in more affluent areas of South Manchester.

Briefly, patients in SLS COPD were aged $\geqslant 40$ years, had a general practitioner (GP) diagnosis of COPD, had experienced $\geqslant 1$ exacerbation of COPD in the previous 3 years and were receiving regular maintenance inhaler therapy [7]. Patients in SLS asthma were aged $\geqslant 18$ years, had a documented GP diagnosis of symptomatic asthma and were receiving regular maintenance inhaler therapy [8]. Both trials had minimal exclusion criteria. In both studies, patients were randomised 1:1 to initiate once-daily inhaled FF/VI $100 \mu \mathrm{g} / 25 \mu \mathrm{g}$ (or $200 \mu \mathrm{g} / 25 \mu \mathrm{g}$ for some patients in SLS asthma, according to GP assessment) or to continue with optimised UC as prescribed by their GP. Randomisation was stratified in SLS COPD by the presence/absence of a COPD exacerbation in the previous 12 months and baseline intended maintenance therapy (long-acting $\beta_{2}$-agonist (LABA), long-acting muscarinic antagonist (LAMA) or LABA/LAMA; inhaled corticosteroid (ICS), ICS/LABA or ICS/LAMA; ICS/LAMA/LABA) and in SLS asthma by baseline Asthma Control Test $(\mathrm{ACT})$ total score $(\leqslant 15 ; 16-19 ; \geqslant 20)$ and baseline intended maintenance therapy (ICS or ICS/LABA). Both studies had a 12-month follow-up period. Treatment modifications were permitted at the GP's discretion throughout the studies (patients could switch from FF/VI to UC but not vice versa). To minimise disruption to patients' everyday lives and preserve the real-world nature of the trials, there were few protocol-mandated visits (screening, randomisation and 12 months/end of study visit); patients were additionally contacted by telephone at the 3-, 6- and 9-month time points for assessment of safety (both trials) and outcome questionnaire assessments, including ACT (SLS asthma only). Medications were dispensed as usual by local community pharmacies, and data were captured remotely and continuously via patients' electronic health records using a primary/secondary care-linked database system $[7,8]$.

\section{Patient consent and ethical approval}

All patients provided written informed consent. The trials were conducted in accordance with the International Conference on Harmonisation Good Clinical Practice guidelines and the provisions of the 2008 Declaration of Helsinki. The trial protocols were approved by the National Research Ethics Service Committee North West, Greater Manchester South (approval numbers 11/NW/0798 and 12/NW/0455).

\section{Assessment of patient deprivation}

A deprivation score for each patient was calculated using patient-level postcodes and a countrywide database of indices of deprivation (version 2010) [9]. This database ranks all areas in England based on their relative level of deprivation, as measured using 38 separate indicators organised across seven distinct domains. Domains can be combined and weighted to produce a single overall Index of Multiple Deprivation, which is used to rank every small area in England according to the deprivation experienced by the people living there [9].

Deprivation scores were used to produce quintiles (quintile 1 being the most deprived and quintile 5 being the least deprived). 


\section{Outcome measures}

These post hoc analyses of patient deprivation focused on the primary effectiveness outcome measures analysed in the main trials, as reported in the primary SLS papers [7, 8]. For SLS COPD, the primary effectiveness outcome was the mean annual rate of moderate/severe exacerbations, defined as any worsening of respiratory symptoms necessitating treatment with antibiotics or systemic glucocorticoids (i.e. moderate exacerbations), or hospitalisation due to a COPD exacerbation (i.e. severe exacerbations). For SLS asthma, the primary effectiveness outcome was the percentage of ACT responders (patients who achieved an ACT total score $\geqslant 20$ and/or an increase from baseline $\geqslant 3$ ) at week 24 . The percentage of ACT responders was also assessed at weeks 12,40 and 52 .

Several secondary and other outcomes were also evaluated, including number of primary care contacts (PCCs), secondary care contacts (SCCs), total direct COPD/asthma-related healthcare costs, treatment adherence (as estimated by the proportion of days covered (PDC) based on study medication prescribing data captured during the study), treatment modifications, patient withdrawals from study, rates of severe asthma exacerbations (SLS asthma only) and incidence of serious adverse events (SAEs), including the pre-specified pneumonia SAE of special interest). Details of outcome measures and their evaluation have been reported previously $[7,8]$.

\section{Statistical analyses}

Analyses of outcomes by deprivation quintile were performed as intent-to-treat (ITT), per randomised treatment group, in the total population, which comprised all randomised patients who received $\geqslant 1$ prescription of study medication. The primary effectiveness outcome for each study was also examined in the primary effectiveness analysis (PEA) population, comprising all patients who had experienced $\geqslant 1$ exacerbation of COPD in the year prior to randomisation (SLS COPD) or who had an ACT total score $<20$ at the randomisation visit (SLS asthma). For SLS asthma, outcomes by deprivation quintile were additionally analysed in the ICS/LABA therapy subset, which comprised patients whose baseline asthma maintenance therapy per randomisation stratification and pre-randomisation prescription was an ICS/LABA.

In the post hoc analyses, the primary effectiveness endpoint for each study was analysed according to the method reported in the respective primary publication $[7,8]$, but with the inclusion of a deprivation quintile and its interaction with the randomised treatment group in each statistical model. For SLS COPD, the primary effectiveness endpoint (mean annual rate of moderate/severe COPD exacerbations) was analysed using a general linear model, assuming a negative binomial distribution. Least squares (LS) mean annual rates, treatment ratios and $95 \%$ confidence intervals (CIs) by deprivation quintile are presented. For SLS asthma, the primary effectiveness endpoint (percentage of ACT responders at week 24) was analysed using logistic regression. Adjusted odds ratios and 95\% CIs for FF/VI versus UC are presented by deprivation quintile. ACT responder analyses were additionally conducted at weeks 12, 40 and 52.

Healthcare resource utilisation data are described as the mean combined annual rates of PCCs/SCCs for FF/VI and UC by deprivation quintile. The interaction of deprivation with treatment effect on PCC/SCC rates was evaluated using a general linear model. Geometric mean total COPD/asthma care costs (costs for COPD/asthma-related healthcare, rescue medication and study drugs) are presented by deprivation quintile and randomised treatment group.

Data for treatment modifications, treatment adherence (PDC) and study withdrawals are summarised by deprivation quintile and randomised treatment group.

The statistical analysis of rates of on-treatment severe asthma exacerbations by randomised treatment group and deprivation quintile was conducted using a general linear model. LS mean annual rates, treatment ratios and 95\% CIs are presented.

The treatment effect of FF/VI versus UC on pneumonia SAE rates by deprivation quintile was analysed using a negative binomial regression model. LS mean annual rates, treatment ratios and 95\% CIs are presented.

The overall aim of this post hoc exploratory work was to establish trends and/or consistency across deprivation quintiles on the outcomes of interest. As such, no adjustments for multiplicity were performed.

\section{Results}

In SLS COPD, $52 \%$ of patients (1453 of 2791) were in the most deprived quintile by postcode, whereas in SLS asthma, deprivation was more equally distributed, with only $20 \%$ of patients (855 of 4218 ) in the most deprived quintile (figure 1). When analysed according to investigators who recruited to both SLS COPD 
FIGURE 1 Patient distribution by deprivation quintile in the Salford Lung Study (SLS) of COPD and the SLS of asthma ltotal study populations). $\mathrm{n}=2791$ and $\mathrm{n}=4218$ patients with available deprivation data for SLS COPD and SLS asthma, respectively. Percentages are based on a denominator of the number of patients with available deprivation data. For deprivation quintile, 1 is the most deprived and 5 is the least deprived.

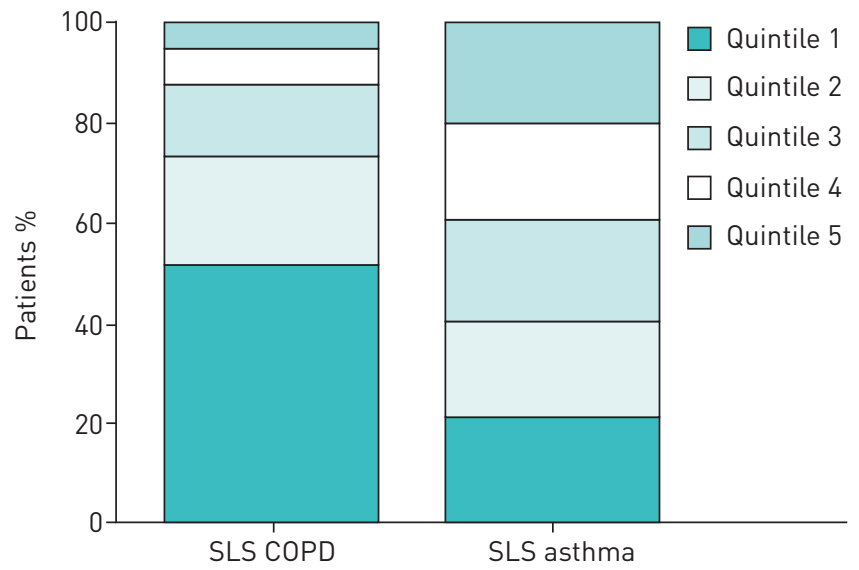

and SLS asthma, patient distribution across the deprivation quintiles was similar to that observed in the overall studies (data not shown).

In SLS COPD, there was a numerical trend toward patients being younger and for a higher proportion of females and current smokers in the more deprived quintiles relative to the least deprived quintiles (table 1). There was also a trend for higher body mass index (BMI) in more deprived patients, but the absolute difference across quintiles may be too small to be clinically relevant. No notable difference in COPD exacerbation history was observed across the deprivation quintiles. Similar trends were observed in SLS asthma, where patients in the more deprived quintiles were numerically more likely to be younger,

TABLE 1 Patient demographics and baseline characteristics by deprivation quintile for the Salford Lung Study (SLS) of COPD and SLS asthma (total study populations)

\begin{tabular}{|c|c|c|c|c|c|}
\hline \multirow[t]{2}{*}{ Characteristic } & \multicolumn{5}{|c|}{ Deprivation quintile } \\
\hline & 1 & 2 & 3 & 4 & 5 \\
\hline \multicolumn{6}{|l|}{ SLS COPD } \\
\hline Patients & $1453 / 2791$ & $601 / 2791$ & $391 / 2791$ & $209 / 2791$ & $137 / 2791$ \\
\hline Age years & $65.0 \pm 9.8$ & $67.2 \pm 10.1$ & $68.8 \pm 9.5$ & $70.4 \pm 8.4$ & $70.1 \pm 9.5$ \\
\hline Males & $733(50)$ & $305(51)$ & $197(50)$ & $111(53)$ & 78 (57) \\
\hline$B M I^{\Uparrow} \mathrm{kg} \cdot \mathrm{m}^{-2}$ & $28.0 \pm 7.1$ & $27.9 \pm 6.1$ & $27.6 \pm 5.4$ & $27.6 \pm 5.4$ & $27.1 \pm 5.0$ \\
\hline Current smokers & $763(53)$ & $247(41)$ & $156(40)$ & 70 (33) & 48 (35) \\
\hline Duration of $C O P D \geqslant 5$ years & 764 (53) & $305(51)$ & $204(52)$ & $127(61)$ & 75 (55) \\
\hline $\begin{array}{l}\text { COPD exacerbations in the year prior to } \\
\text { randomisation }\end{array}$ & $2.1 \pm 2.1$ & $1.9 \pm 1.8$ & $2.0 \pm 1.8$ & $2.0 \pm 1.9$ & $1.5 \pm 1.4$ \\
\hline \multicolumn{6}{|l|}{ SLS asthma } \\
\hline Patients & $855 / 4218$ & $834 / 4218$ & $856 / 4218$ & $831 / 4218$ & $842 / 4218$ \\
\hline Age years & $47.1 \pm 15.8$ & $47.9 \pm 16.0$ & $49.9 \pm 16.2$ & $50.0 \pm 16.9$ & $54.1 \pm 16.0$ \\
\hline Males & $346(40)$ & $330(40)$ & $359(42)$ & $344(41)$ & $353(42)$ \\
\hline$B M I^{\Uparrow} \mathrm{kg} \cdot \mathrm{m}^{-2}$ & $31.0 \pm 7.6$ & $30.6 \pm 7.1$ & $30.4 \pm 7.1$ & $29.1 \pm 6.2$ & $28.5 \pm 5.8$ \\
\hline Current smokers" & 276 (33) & $218(26)$ & $179(21)$ & $108(13)$ & $65(8)$ \\
\hline Duration of asthma $\geqslant 10$ years & $627(73)$ & $624(75)$ & $634(74)$ & $611(74)^{9}$ & $638(76)$ \\
\hline $\begin{array}{l}\text { Severe asthma exacerbations in the year } \\
\text { prior to randomisation }\end{array}$ & $0.7 \pm 1.2$ & $0.7 \pm 1.2$ & $0.7 \pm 1.3$ & $0.6 \pm 1.0$ & $0.5 \pm 0.9$ \\
\hline Uncontrolled asthma ${ }^{+}$ & $462(54)^{\pi}$ & $384(46)$ & $354(41)$ & $282(34)$ & $231(27)$ \\
\hline $\begin{array}{l}\text { Daytime symptoms more than twice a } \\
\text { week }^{\S}\end{array}$ & $772(90)$ & 760 (91) & $781(91)$ & $750(90)$ & $755(90)$ \\
\hline SABA use more than twice a week $k^{\S}$ & $689(81)$ & $648(78)$ & $640(75)$ & $552(66)$ & $504(60)$ \\
\hline Activity limitations in the past week ${ }^{\S}$ & 501 (59) & $474(57)$ & $454(53)$ & $374(45)$ & $351(42)$ \\
\hline $\begin{array}{l}\text { Nocturnal symptoms/awakenings in the } \\
\text { past week }\end{array}$ & 504 (59) & $446(53)$ & $409(48)$ & $383(46)$ & $365(43)$ \\
\hline \multicolumn{6}{|c|}{$\begin{array}{l}\text { Data are presented as } \mathrm{n} / \mathrm{N}, \text { mean } \pm \mathrm{SD} \text { or } \mathrm{n}(\%) \text {. BMI: body mass index; SABA: short-acting } \beta_{2} \text {-agonist. } \\
\# \text { : where } 1 \text { is the most deprived and } 5 \text { is the least deprived; " : based on patients with available data; } \\
{ }^{*}: \text { Asthma Control Test score } \leqslant 15 ;{ }^{\S} \text { : based on patients' recall of asthma symptoms in the past week, as } \\
\text { assessed at the baseline (randomisation) visit. }\end{array}$} \\
\hline
\end{tabular}


to smoke, to have a higher BMI, to have uncontrolled asthma (ACT total score $\leqslant 15$ ) and to have recent asthma symptoms (rescue medication use, activity limitations and night-time symptoms/awakenings) relative to patients in the less deprived quintiles (table 1). There was no notable difference in asthma exacerbation history across the deprivation quintiles. Characteristics of patients in the SLS asthma ICS/LABA therapy subset were generally similar to the total study population (supplementary table S1).

In SLS COPD, the treatment effect of initiating FF/VI versus continuing UC on the mean annual rate of moderate/severe exacerbations across deprivation quintiles was broadly similar to the overall PEA population (figure 2a). In SLS asthma, there was a consistent benefit for FF/VI over UC for the percentage of ACT responders at week 24 across the deprivation quintiles in the PEA population (figure 2b); a similar benefit for FF/VI versus UC was also observed at weeks 12, 40 and 52 in each deprivation quintile in the

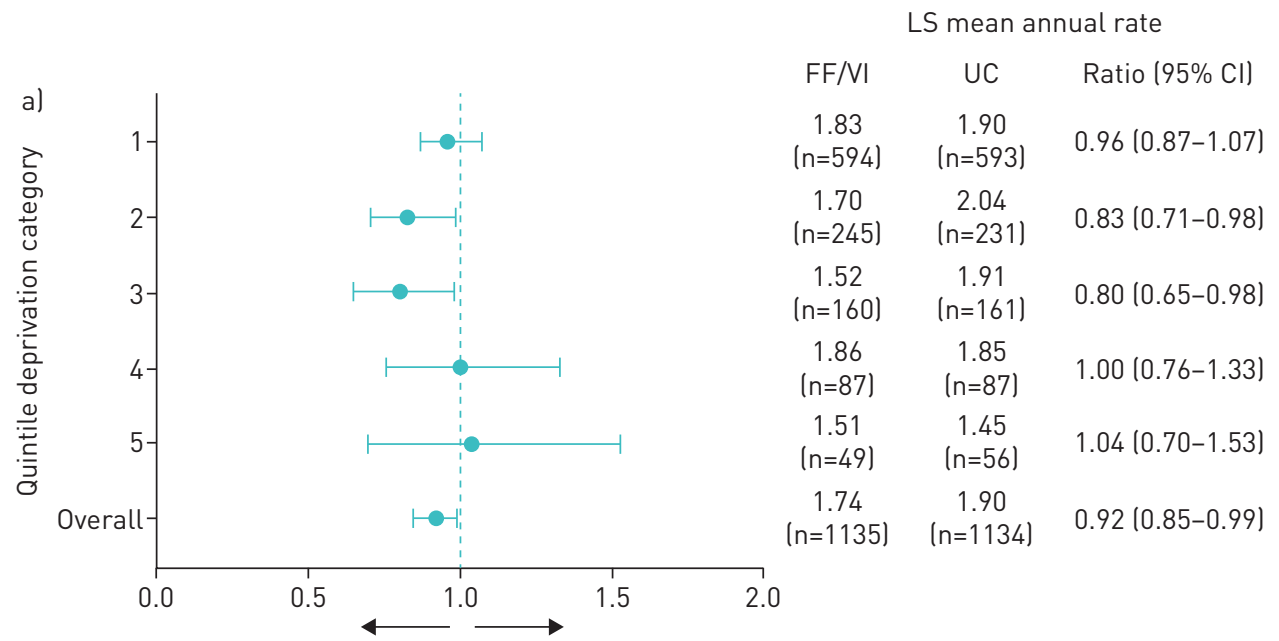

Favours FF/VI Favours UC Ratio

ACT responders at week 24

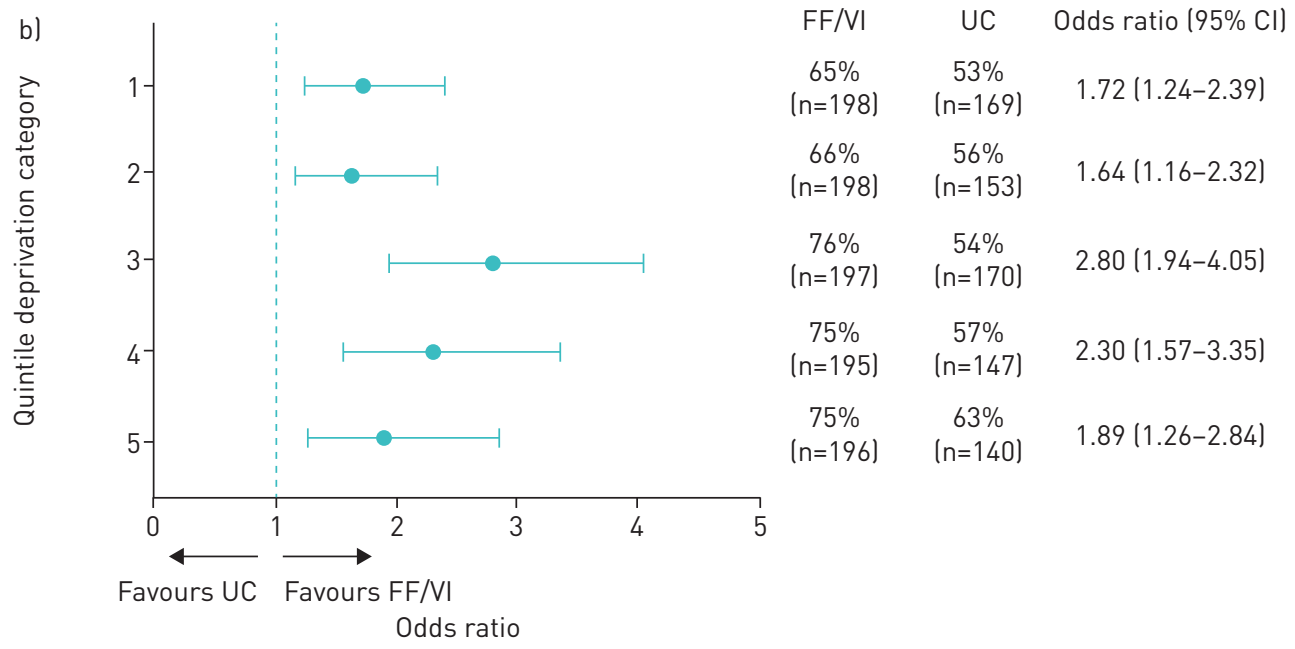

FIGURE 2 Primary effectiveness outcomes by treatment group and deprivation quintile. a) Salford Lung Study (SLS) of COPD: mean annual rate of moderate/severe exacerbations (primary effectiveness analysis (PEA) population, $n=2269$ ). Moderate/severe exacerbations are defined as reported previously [7]. Analysis using a general linear model assuming a negative binomial distribution, with the logarithm of time on treatment as an offset variable and adjusting for randomised treatment, baseline COPD maintenance therapy per randomisation stratification, number of prior moderate/severe COPD exacerbations in the previous year, baseline smoking status, deprivation quintile and a randomised treatment-by-deprivation quintile interaction term. For deprivation quintile, 1 is the most deprived and 5 is the least deprived. b) SLS asthma: percentage of Asthma Control Test (ACT) responders at week 24 (PEA population; $n=3015$ ). ACT responders were defined as patients who achieved an ACT total score $\geqslant 20$ and/or increase from baseline $\geqslant 3$. Analysis by logistic regression with adjustment for randomised treatment, baseline ACT total score, baseline ACT total score squared, asthma maintenance therapy at baseline per randomisation stratification, age, sex, baseline smoking status, deprivation quintile and a randomised treatment-by-deprivation quintile interaction term. FF/VI: fluticasone furoate/vilanterol; UC: usual care; LS: least squares. 
PEA population (figure 3) and at weeks 12, 24, 40 and 52 in the ICS/LABA therapy subset of the PEA population (supplementary figure S1).

In both trials, higher rates of PCCs/SCCs were observed in the more deprived quintiles relative to less deprived quintiles (table 2), but there was no apparent interaction of deprivation quintile with treatment effect for FF/VI versus UC. Care costs were higher for more deprived patients with COPD, but not for those with asthma. There was no consistent impact of deprivation on treatment adherence, treatment modification rates, patient withdrawals from study (tables 3-5) or on-treatment severe asthma exacerbations (supplementary table S2). There were small differences in the incidence of on-treatment SAEs between the most and least deprived patients in both the COPD and asthma studies, but no difference in SAE incidence between randomised treatment groups in each of the deprivation quintiles. There was no difference in pneumonia SAE incidence between randomised treatment groups in each of the deprivation quintiles in SLS COPD (supplementary table S3). In SLS asthma, the on-treatment pneumonia SAE incidence was $<1 \%$ of all patients [10] and analysis by deprivation quintile was not conducted.

\section{Discussion}

Salford is a typical urban area in North West England and a substantial proportion of the population live in socioeconomically deprived areas. Over half of patients in SLS COPD were categorised in the most deprived quintile, compared to $20 \%$ of patients in SLS asthma. Higher healthcare resource utilisation and care costs in more deprived patients could be linked to the observed differences in baseline patient characteristics (i.e. higher proportions of current smokers and a trend for higher BMI in the more deprived quintiles). Indeed, deprivation has previously been identified as a risk factor for COPD hospital admissions [11]. The level of deprivation did not influence any of the main clinical effectiveness and safety outcomes in the SLS, indicating that the overall trial results are relevant to all patients with asthma and COPD in routine care.

The major strengths of this study relate to the pragmatic trial design of the SLS, successful recruitment of patients from all socioeconomic strata and the richness of the dataset. We were able to access deprivation data for almost all randomised patients $(n>7000)$ and capture healthcare contacts data using a primary/secondary

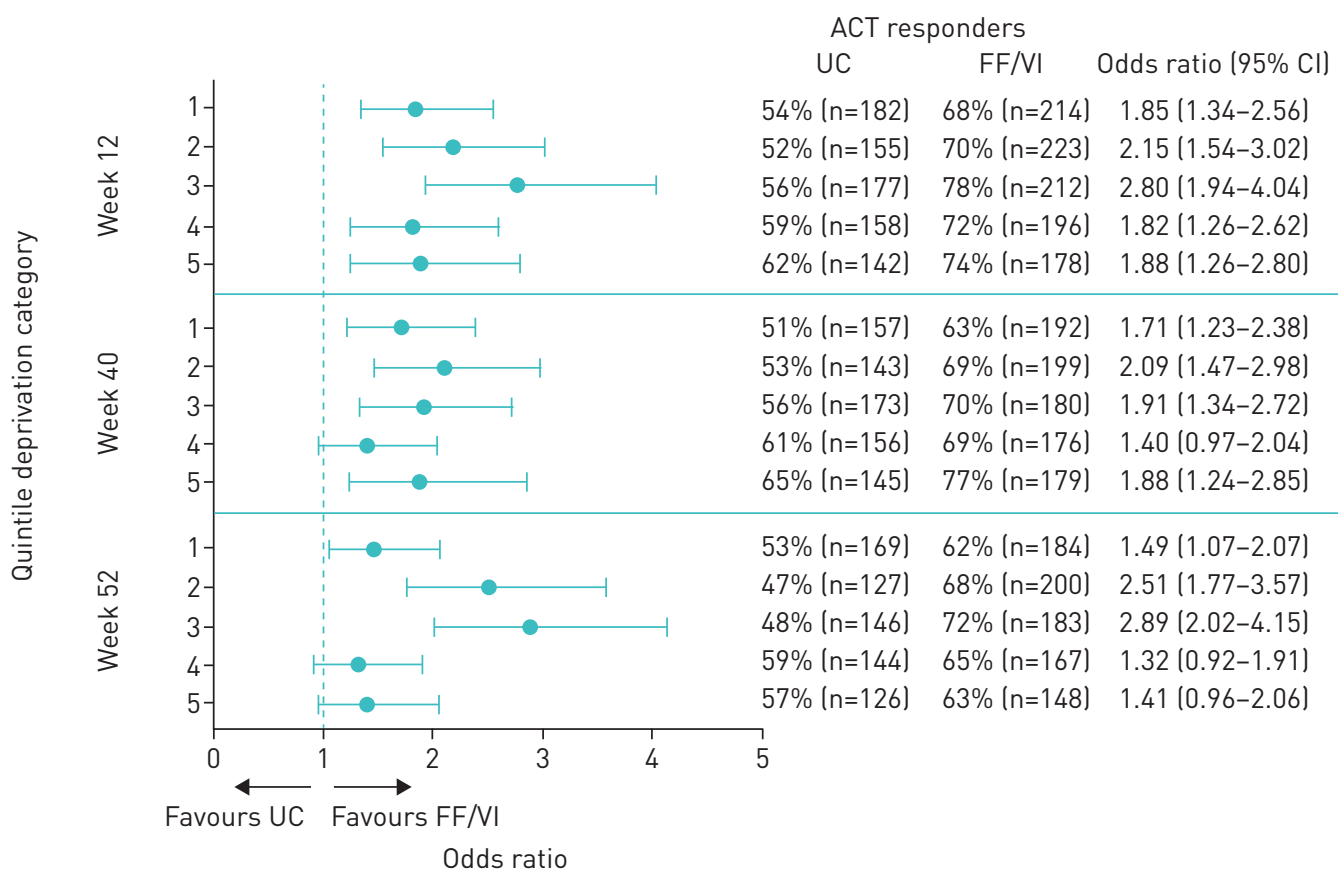

FIGURE 3 Percentage of Asthma Control Test (ACT) responders at weeks 12, 40 and 52 by treatment group stratified by deprivation quintile in the Salford Lung Study of asthma (primary effectiveness analysis population; $n=3015$ ). ACT responders were defined as patients who achieved an ACT total score $\geqslant 20$ and/or increase from baseline $\geqslant 3$. Analysis by logistic regression with adjustment for randomised treatment, baseline ACT total score, baseline ACT total score squared, asthma maintenance therapy at baseline per randomisation stratification, age, sex, baseline smoking status, deprivation quintile and a randomised treatment-by-deprivation quintile interaction term. For deprivation quintile, 1 is the most deprived and 5 is the least deprived. UC: usual care; FF/VI: fluticasone furoate/vilanterol 
TABLE 2 Healthcare contacts ${ }^{\#}$ and care costs by deprivation quintile in the Salford Lung Study (SLS) of COPD and SLS asthma (total study populations)

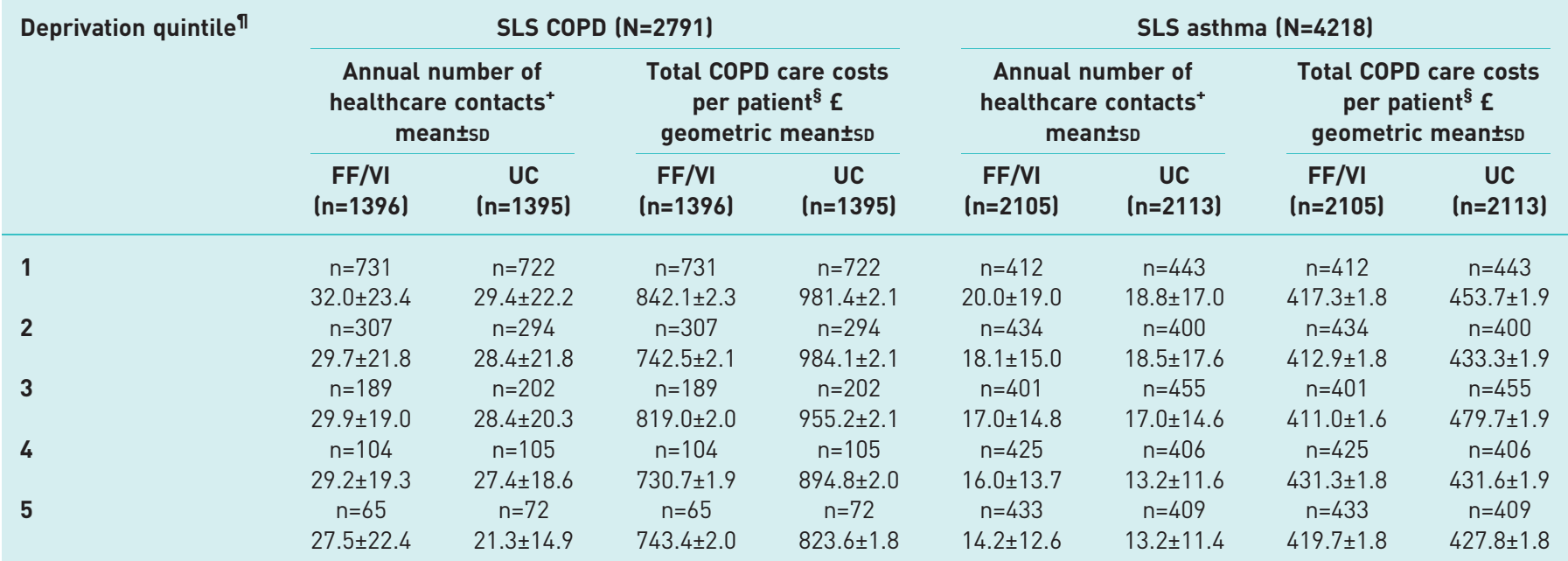

FF/VI: fluticasone furoate/vilanterol; UC: usual care. " : on-treatment, all-cause healthcare contacts; ": where 1 is the most deprived and 5 is the least deprived; ${ }^{+}$: composite analysis of all primary and secondary healthcare contacts; ${ }^{\S}$ : including total direct costs for COPD/ asthma-related healthcare resource utilisation, rescue medication and study drugs.

care-linked electronic database. Weaknesses include the post hoc nature of these analyses, which were conducted without multiplicity adjustment. Furthermore, the high proportion of deprived patients in SLS COPD (in contrast to SLS asthma) resulted in small sample sizes for some deprivation quintiles, limiting results interpretation. Another limitation is that patients were allocated into deprivation quintiles based on ranking of deprivation scores derived by postcode, rather than based on individual characteristics. It could be argued, therefore, that patients allocated to the most deprived quintiles in this study may not necessarily themselves be truly socioeconomically deprived. Such detailed socioeconomic information was not available on an individual patient basis in this study. It is noteworthy, however, that Salford is listed as one of the top 20 local authorities in England with the highest proportions of areas that are among the

TABLE 3 Treatment adherence (proportion of days covered) by deprivation quintile in the Salford Lung Study (SLS) of COPD and SLS asthma (total study populations and SLS asthma inhaled corticosteroid (ICS)/long-acting $\beta_{2}$-agonist (LABA) therapy subset ${ }^{\#}$ )

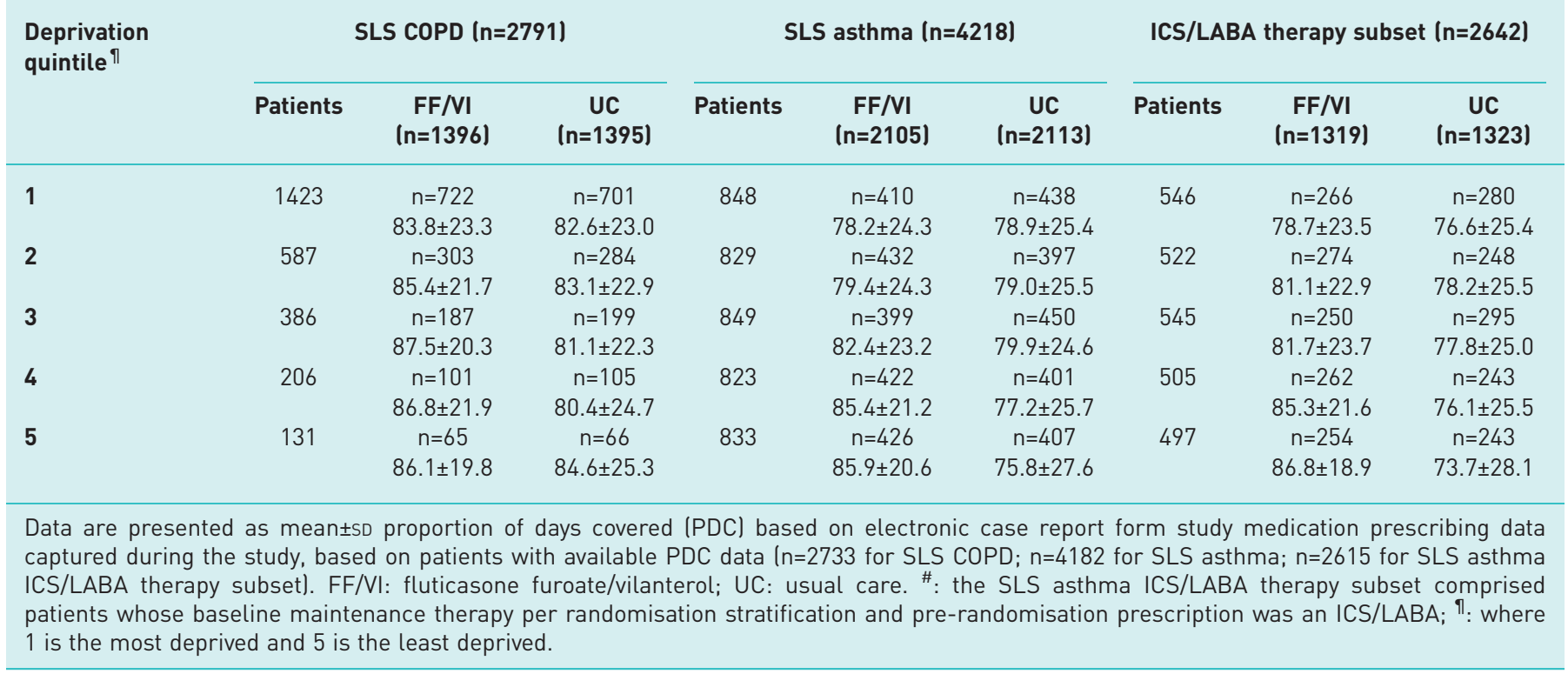


TABLE 4 Treatment modifications by deprivation quintile in the Salford Lung Study (SLS) of COPD and SLS asthma (total study populations and SLS asthma inhaled corticosteroid (ICS)/long-acting $\beta_{2}$-agonist (LABA) therapy subset $\#$ )

\begin{tabular}{|c|c|c|c|c|c|c|c|c|c|}
\hline \multirow{2}{*}{$\begin{array}{c}\text { Deprivation } \\
\text { quintile }^{\pi}\end{array}$} & \multicolumn{3}{|c|}{ SLS COPD $(n=2791)$} & \multicolumn{3}{|c|}{ SLS asthma ( $n=4218)$} & \multicolumn{3}{|c|}{ ICS/LABA therapy subset $(n=2642)$} \\
\hline & Patients & $\begin{array}{c}F F / V I \\
(n=1396)\end{array}$ & $\begin{array}{c}\text { UC } \\
\text { (n=1395) }\end{array}$ & Patients & $\begin{array}{c}F F / V I \\
(n=2105)\end{array}$ & $\begin{array}{c}\text { UC } \\
(n=2113)\end{array}$ & Patients & $\begin{array}{c}F F / V I \\
(n=1319)\end{array}$ & $\begin{array}{c}\text { UC } \\
(n=1323)\end{array}$ \\
\hline 1 & 1453 & $\begin{array}{c}n=731 \\
181(25 \%)\end{array}$ & $\begin{array}{c}n=722 \\
78(11 \%)\end{array}$ & 855 & $\begin{array}{c}n=412 \\
82(20 \%)\end{array}$ & $\begin{array}{c}n=443 \\
113(26 \%)\end{array}$ & 551 & $\begin{array}{c}n=268 \\
62(23 \%)\end{array}$ & $\begin{array}{c}n=283 \\
80(28 \%)\end{array}$ \\
\hline 2 & 601 & $\begin{array}{c}n=307 \\
69(22 \%)\end{array}$ & $\begin{array}{c}n=294 \\
37(13 \%)\end{array}$ & 834 & $\begin{array}{c}n=434 \\
94(22 \%)\end{array}$ & $\begin{array}{c}n=400 \\
65(16 \%)\end{array}$ & 526 & $\begin{array}{c}n=276 \\
59(21 \%)\end{array}$ & $\begin{array}{c}n=250 \\
40(16 \%)\end{array}$ \\
\hline 4 & 209 & $\begin{array}{c}n=104 \\
26(25 \%)\end{array}$ & $\begin{array}{c}n=105 \\
16(15 \%)\end{array}$ & 831 & $\begin{array}{c}n=425 \\
94(22 \%)\end{array}$ & $\begin{array}{c}n=406 \\
64(16 \%)\end{array}$ & 511 & $\begin{array}{c}n=265 \\
61(23 \%)\end{array}$ & $\begin{array}{c}n=246 \\
44(18 \%)\end{array}$ \\
\hline 5 & 137 & $\begin{array}{c}n=65 \\
26(40 \%)\end{array}$ & $\begin{array}{c}n=72 \\
10(14 \%)\end{array}$ & 842 & $\begin{array}{c}n=433 \\
103(24 \%)\end{array}$ & $\begin{array}{c}n=409 \\
53(13 \%)\end{array}$ & 503 & $\begin{array}{c}n=258 \\
73(28 \%)\end{array}$ & $\begin{array}{c}n=245 \\
37(15 \%)\end{array}$ \\
\hline
\end{tabular}

TABLE 5 Rates of patient withdrawals from study by deprivation quintile in the Salford Lung Study (SLS) of COPD and SLS asthma (total study populations and SLS asthma inhaled corticosteroid (ICS)/long-acting $\beta_{2}$-agonist (LABA) therapy subset ${ }^{\#}$ )

\begin{tabular}{|c|c|c|c|c|c|c|c|c|c|}
\hline \multirow{2}{*}{$\begin{array}{c}\text { Deprivation } \\
\text { quintile" }^{\text {q }}\end{array}$} & \multicolumn{3}{|c|}{ SLS COPD $(n=2791)$} & \multicolumn{3}{|c|}{ SLS asthma ( $n=4218)$} & \multicolumn{3}{|c|}{ ICS/LABA therapy subset $(n=2642)$} \\
\hline & Patients & $\begin{array}{c}F F / V I \\
(n=1396)\end{array}$ & $\begin{array}{c}\text { UC } \\
\text { (n=1395) }\end{array}$ & Patients & $\begin{array}{c}F F / V I \\
(n=2105)\end{array}$ & $\begin{array}{c}\text { UC } \\
(n=2113)\end{array}$ & Patients & $\begin{array}{c}F F / V I \\
(n=1319)\end{array}$ & $\begin{array}{c}U C \\
(n=1323)\end{array}$ \\
\hline \multirow[t]{2}{*}{1} & 1453 & $n=731$ & $n=722$ & 855 & $n=412$ & $n=443$ & 551 & $n=268$ & $\mathrm{n}=283$ \\
\hline & & $54(7 \%)$ & $53(7 \%)$ & & $40(10 \%)$ & $37(8 \%)$ & & $23(9 \%)$ & $18(6 \%)$ \\
\hline 2 & 601 & $n=307$ & $n=294$ & 834 & $n=434$ & $n=400$ & 526 & $n=276$ & $n=250$ \\
\hline 3 & & $12(6 \%)$ & $15(7 \%)$ & & $32(8 \%)$ & $38(8 \%)$ & & $20(8 \%)$ & $26(9 \%)$ \\
\hline \multirow[t]{2}{*}{4} & 209 & $n=104$ & $\mathrm{n}=105$ & 831 & $n=425$ & $n=406$ & 511 & $\mathrm{n}=265$ & $n=246$ \\
\hline & & $9(9 \%)$ & $7(7 \%)$ & & $37(9 \%)$ & $30(7 \%)$ & & $23(9 \%)$ & $18(7 \%)$ \\
\hline \multirow[t]{2}{*}{5} & 137 & $n=65$ & $\mathrm{n}=72$ & 842 & $n=433$ & $n=409$ & 503 & $n=258$ & $n=245$ \\
\hline & & $4(6 \%)$ & $3(4 \%)$ & & 37 (9\%) & $24(6 \%)$ & & $20(8 \%)$ & $14(6 \%)$ \\
\hline
\end{tabular}

$10 \%$ most deprived [9]; it follows, therefore, that the SLS likely did include patients who were genuinely of lower socioeconomic status.

Overall, our data support the view that patients' socioeconomic status should not be a barrier to participation in RCTs, and that enrolment of a broad patient population should be actively encouraged. Routine reporting of data on patients' baseline socioeconomic status will allow for assessment of generalisability of trial results in comparison to patients in routine clinical practice.

Acknowledgements: Editorial support (in the form of editorial suggestions to draft versions of this paper, assembling tables and figures, collating author comments, and copyediting, referencing and graphic services) was provided by Emma Landers of Gardiner-Caldwell Communications (GCC; Macclesfield, UK) and was funded by GlaxoSmithKline plc.

Author contributions: The authors contributed to the study as follows. R. Jones: study concept, data analysis/ interpretation, manuscript writing/review and approval of the final version submitted. A. Nicholls: statistical analysis planning and review (accountability) for the ad hoc work, and manuscript writing/review and approval of the final version submitted. D. Browning: data analysis/interpretation, manuscript writing/review and approval of the final 
version submitted. N. Diar Bakerly: study conception/design, data acquisition, data analysis/interpretation, and manuscript writing/review and approval of the final version submitted. A. Woodcock: study conception/design, data analysis/interpretation, and manuscript writing/review and approval of the final version submitted. J. Vestbo: contributed to the overall study design and analysis, the interpretation of the data presented in this manuscript and revision of the primary manuscript, manuscript writing/review and approval of the final version submitted. D.A. Leather: conceived the original study concept, contributed to protocol development, analysis plan, data interpretation, study operations, manuscript writing/review and approval of the final version submitted. L. Jacques: data analysis/interpretation, manuscript writing/review and approval of the final version submitted. J. Lay-Flurrie: data analysis/interpretation, manuscript writing/review and approval of the final version submitted. H. Svedsater: study conception/design, data analysis/interpretation, manuscript writing/review and approval of the final version submitted. S. Collier: data acquisition, data analysis/interpretation, manuscript writing/review and approval of the final version submitted.

Conflict of interest: R. Jones reports that this study was funded by GlaxoSmithKline plc. and medical writing support by GCC was also funded by GlaxoSmithKline plc. He also reports grants, personal fees and nonfinancial support from AstraZeneca and GlaxoSmithKline plc., personal fees and nonfinancial support from Boehringer Ingelheim, Novartis and Nutricia, and personal fees from Pfizer, outside the submitted work. A. Nicholls reports that this study was funded by GlaxoSmithKline plc. and medical writing support by GCC was also funded by GlaxoSmithKline plc. He is an employee of and holds shares/options in GlaxoSmithKline plc. D. Browning reports that this study was funded by GlaxoSmithKline plc. and medical writing support by GCC was also funded by GlaxoSmithKline plc. She is an employee of and holds shares/options in GlaxoSmithKline plc. N. Diar Bakerly reports that this study was funded by GlaxoSmithKline plc. and medical writing support by GCC was also funded by GlaxoSmithKline plc. A. Woodcock reports that this study was funded by GlaxoSmithKline plc. and medical writing support by GCC was also funded by GlaxoSmithKline plc. He also reports startup companies in the fields of chronic cough (Axalbion) and food allergy (Reacta Biotech), and that he is the unpaid chairman of a clinical trials company (Medicines Evaluation unit), outside the submitted work. J. Vestbo reports that this study was funded by GlaxoSmithKline plc. and medical writing support by GCC was also funded by GlaxoSmithKline plc. He also reports fees for advising on phase II and III studies as well as presenting from AstraZeneca and Novartis; an unconditional biomarker grant, and fees for advising on phase II and III studies as well as presenting from Boehringer Ingelheim; and fees for advising on phase II and III studies as well as presenting, and travel and accommodation for the ERS International Congress 2018 from Chiesi, all outside the submitted work. In addition, his son works for Chiesi (Denmark). D.A. Leather reports that this study was funded by GlaxoSmithKline plc. and medical writing support by GCC was also funded by GlaxoSmithKline plc. He is an employee of and holds shares/options in GlaxoSmithKline plc. L. Jacques reports that this study was funded by GlaxoSmithKline plc. and medical writing support by GCC was also funded by GlaxoSmithKline plc. She is an employee of and holds shares/options in GlaxoSmithKline plc. J. Lay-Flurrie reports that this study was funded by GlaxoSmithKline plc. and medical writing support by GCC was also funded by GlaxoSmithKline plc. He is an employee of and holds shares/options in GlaxoSmithKline plc. H. Svedsater reports that this study was funded by GlaxoSmithKline plc. and medical writing support by GCC was also funded by GlaxoSmithKline plc. He is an employee of and holds shares/options in GlaxoSmithKline plc. S. Collier reports that this study was funded by GlaxoSmithKline plc. and medical writing support by GCC was also funded by GlaxoSmithKline plc. She is an employee of and holds shares/options in GlaxoSmithKline plc.

Support statement: SLS COPD (HZC115151 and NCT01551758) and SLS asthma (HZA115150 and NCT01706198) were funded by GlaxoSmithKline plc. R. Jones is supported by the National Institute for Health Research (NIHR) Collaboration for Leadership in Applied Health Research and Care South West Peninsula. A. Woodcock and J. Vestbo are supported by the NIHR Manchester Biomedical Research Centre.

\section{References}

1 Gershon AS, Dolmage TE, Stephenson A, et al. Chronic obstructive pulmonary disease and socioeconomic status: a systematic review. COPD 2012; 9: 216-226.

2 British Lung Foundation. Asthma Statistics. https://statistics.blf.org.uk/asthma Date last accessed: July 22, 2019. Date last updated: 2020.

3 British Lung Foundation. Chronic Obstructive Pulmonary Disease (COPD) Statistics. https://statistics.blf.org.uk/copd Date last accessed: July 22, 2019. Date last updated: 2020.

4 Kruis AL, Ställberg B, Jones RC, et al. Primary care COPD patients compared with large pharmaceutically-sponsored COPD studies: an UNLOCK validation study. PLoS One 2014; 9: e90145.

5 Herland K, Akselsen JP, Skjønsberg OH, et al. How representative are clinical study patients with asthma or COPD for a larger "real life" population of patients with obstructive lung disease? Respir Med 2005; 99: 11-19.

6 Scichilone N, Basile M, Battaglia S, et al. What proportion of chronic obstructive pulmonary disease outpatients is eligible for inclusion in randomized clinical trials? Respiration 2014; 87: 11-17.

7 Vestbo J, Leather D, Diar Bakerly N, et al. Effectiveness of fluticasone furoate-vilanterol for COPD in clinical practice. N Engl J Med 2016; 375: 1253-1260.

8 Woodcock A, Vestbo J, Bakerly ND, et al. Effectiveness of fluticasone furoate plus vilanterol on asthma control in clinical practice: an open-label, parallel group, randomised controlled trial. Lancet 2017; 390: 2247-2255.

9 Department for Communities and Local Government. The English Indices of Deprivation 2010. www.gov.uk/ government/uploads/system/uploads/attachment_data/file/6871/1871208.pdf Date last accessed: July 22, 2019. Date last updated: March 2011.

10 GlaxoSmithKline. GSK Clinical Study Register. Study HZA115150 Clinical Study Report. http://s3.amazonaws. com/ctr-gsk-7381/115150/6445927f-953c-402f-a79a-6ca22d93169c/ele0596f-8dc8-4212-9e04-ce2a778d0e6d/gsk115150-clinical-study-report-redact-v1.pdf Date last accessed: July 22, 2019. Date last updated: 29 September 2017.

11 Calderón-Larrañaga A, Carney L, Soljak M, et al. Association of population and primary healthcare factors with hospital admission rates for chronic obstructive pulmonary disease in England: national cross-sectional study. Thorax 2011; 66: 191-196. 